of the circulation at which they can make their way into the surrounding tissues. In some cases bacilli are present in the emboli, or they may be actually distributed in the embolic area, in many cases appearing to make their way from the capillary vessels into the lymph spaces, and only then giving rise to the characteristic series of changes.

\section{The Curability of Phthisis.}

It was long unfortunate (but natural', for the sake of prognosis, that only the worst cases were seen in the post-mortem room, but in the present day tubercle has come to be looked upon as a comparatively curable disease. After some experience in the post-mortem theatres of a large general hospital and a children's hospital, the author felt convinced that the recent change which has come over medical opinion as regards the curability of phthisis in the early stage is thoroughly justified by facts. In proof of this there are the numerous localised fibroid and deeply pigmented bands of tissue seen in the lungs of old people, or people who have died during middle life, sometimes without caseous or calcareous nodules in the centre, but perhaps more frequently with one or other of these marking the centre of the cicatrix, the puckered pleura near the apex of the lung also marking a considerable loss of substance at some period during life. In children this is not found in nearly such a large proportion of cases, but well-marked examples may be met with even in very early life, and pretty frequently before the eighth year.

This is so far encouraging, and entitles us to hope that, as more facts concerning the life history of the bacillus tuberculosis and the conditions under which it may flourish in the body are gathered, the death-rate from tuberculosis may be materially diminished. Milk, air, and food can one and all convey the bacillus from cattle or swine to patient, or from patient to patient; and if the bacillus or the disease can be successfully attacked in any one of these, a possible source of infection to others is done away with. From clinical experience it must now be concluded that the general health of the patient bas in all cases much to do with the resisting powers of the tissues, so it is imperative on every medical man to try to improve the general health of those of his patients having a tendency to scrofula or a tubercular family history. Children of low vitality are scrofulous because the introduction of a comparatively small number of bacilli brings about complete degeneration of the lymphatic glands, and there are no giant cells and few bacilli found in a scrofulous gland, not because of any change in the nature of the bacilli, but because of the difference (non-resistance) of the tissues in which they grow. The number of bacilli attacking a healthy gland would be rapidly disposed of; but in the delicate child, with its weakly tissues and imperfect nutritive and excretory power, the gland tissue gives way on the slightest stimulation, and the cold abscess is the result. The author was convinced from the experiments he had performed that this was the case. Bacilli differ in number, but not in character; and if once a cultivation can be obtained from a cold abscess (a somewhat difficult matter), well-marked tuberculosis may be produced by it by inoculation.

\section{A CRITICISM ON THE HOSPITAL PLANS ISSUED BY THE LOCAL GOVERNMENT BOARD.}

A Documenr, consisting of plans and letterpress, has been issued by the Medical Department of the Local Government Board, intended as a guide to those local authorities who desire to provide means means of isolation for infectious cases.

The author says "It cannot be too clearly understood that an isolation hospital, to fulfil its proper purpose of sanitary defence, ought to be in readiness beforehand. During the progress of an epidemic it is of little avail to set about hospital construction. The mischief of allowing infection to spread from first cases will already have been done, and this mischief cannot be repaired." A saying worthy of all acceptation, and one which may well be impressed on every sanitary authority. We are generally in full accord with the author in most of his remarks and advice with reference to cubic space, floor spaces, distance of wards from other buildings and from boundary fence: but we regret being unable to approve of all, or even of most, of the arrangements recommended in the construction of the hospitals. Tacked to the letterpress are three sheets of plans, representing four hospitals of different sizes. The first is arranged for four beds. The doors of the wards and of the nurses' rooms open direct into a verandah without any intermediary lobby or porch. The nurses' duty tooms very properly overlook thedormitories, and their sleeping rooms are to be provided either by a first floor over the central part of the hospital, or in the caretaker's cottage. The latter alternative has nothing to recommend it, unless it be thought desirable for the nurses to sleep away from the infected atmosphere; but this would not apply in a well-ventilated, properly constructed hospital. The wash-house and mortuary are also in a separate building; consequently, to provide space enough to treat two men and two women afficted with fever, it is advised to have three detached buildings placed at some distance from each other, and with no means of reaching one from the other, without passing into the open air. Fancy this arrangement with a foot of snow on the ground, or a cold east wind blowing, or a pelting rain from 
south-west! Bath rooms and water-closets are not shown in the hospital plan, but a note informs us that portable baths and earth commodes will be required.

The second plan is for a six-bedded hospital, and is designed for the isolation of two sets of patients suffering from different infectious maladies. There are therefore two dormitories for men and two for women. As, however, only one nurse's room is shown for each division, and indeed more than one could hardly be afforded in so small a hospital, it is to be feared that the same nurse would have to attend both classes of patients, so that the risk of interchanging diseases would only be a little reduced, not prevented. The building is a long narrow one, and is probably intended to face north and south. The men's wards have a verandah on one aspect, and the women's on the other. There is a similar arrangement here as to the ward doors as in the rirst plan; but it seems more objectionable than in the smaller one. The roof of the verandah is so planned that it does not run close to the eaves, but at a point which apparently marks the division of the window into sash and hopper. This is a sensible idea. The w.c.'s and sinks are placed on the outer aspect of the verandahs, and patients, perhaps convalescing from smallpox or measles, would either have to cross the verandah, often more draughty than the open air, or use earth commodes in the wards. No bath-rooms are shown. Now, it is practically certain that with the cessation of the fever ceases also the production of new infectious matter, and to get rid of that which has already been generated no course is so trustworthy as tepid baths frequently repeated. A portable bath is a very useful adjunct to a ward, but if it be relied on solely, and warm water have to be carried to the rooms, it is more than likely the baths would not be used nearly often enough, especially as there would be no resident medical officer to see his orders carried out. The nurses' sleeping-rooms, kitchen, etc., are presumably intended to be in a detached block as they are not shown on the plan.

The third plan is the best, and with certain minor alterations and the administrative department properly incorporater, might be recommended for adoption.

The fourth plan is much the same as the second one, and our remarks apply equally to it. It is, however, of larger size, and is constructed for ten patients. The end dormitories are placed at right angles to the rest of the building, and are lighted almost entirely from the ends. The length is abott thirty-five feet, and in a calm day this would be a long way for an efficient cross current. Surely one or two windows might have been placed in the blank wall.

On reviewing the whole document we are almost tempted to believe that the letterpress is the work of one man and the plans of another.

\section{BREATHING SPACES FOR LONDON.}

LONDON is largely overpopulated. In nine years (from 1872 to 1881 ) there has been an average increase of 8.3 persons to an acre. If this continues - and there is no reason to suppose that it will not-it is hardly false to predict that the health of the residents in the metropolis must deteriorate if more stretches of land be not secured free from buildings. These breathingspaces would not morely benefit the comparative few who dwell in their immediate neighbourhood, but would mitigate the airlessness of the whole city, more especially if trees and shrubs were planted to supply the necessary ozone.

With this object in view the Metropolitan Public Gardens Association was started, and in the four years that it has been working it has succesded in securing for the public forty-six open spaces in different parts of London. Of these ten are playgrounds and thirty-six "gardens," which last were little worthy the name till they were taken in hand by Miss Wilkinson (Landscape Gardener to the Association), as they were mostly either locked-up desertedlooking squares or exceedingly neglected disused burial grounds. If the latter, the first step was to obtain a Faculty, which generally permitted the removal of such tomb-stones as no one put in a claim to have kept. These stones, after being carefully numbered, wero placed against the walls, and well planted out; turf was laid, paths and plantations made, and a good number of seats placed.

In all the gardens there are fountains, both drinking and ornamental, and as every season comes round bright flowers are put in the beds.

Much, however, yet remains to be done. Almost. daily new houses spring up (their rate of increase being computed at between six and seven thousand a year), and that means so many more individuals and chimneys to absorb and corrupt the already impure air. Ground is so valuable, and flats for all classes so much in request, that many of the houses are built with a vast number of stories which tend to prevent the free circulation of air through the streets. Think of the enormons Hankey and Queen Anne's Mansions, and also of the numerous and large artizans' dwellings that are seattered about London-in Lisson Grove alone there are five such blocks of flats for the working classes. Or take those in the East Endsay in Red Cross Street, Southwark. Here the street is exceedingly narrow, and the air particularly stifling, till you get to a tiny garden (flanked on three sides by houses) which the Kyrle Society has obtained and laid out for public recreation. It is particularly useful, being situated opposite many-storied flats, and in a neighbourhood where most of the houses are far greater in height than the street is in width. In London distances are 
so great that the number of open spaces needs to be correspondingly great that the densest and most thickly populated quarters may be at least healthily habitable to all who cannot afford the spring or autumm change of air.

Aecording to the statistics compiled by Mrs. Holmes we find that at one time and another at least 443 burial grounds have existed in London. Of these only 69 are open to the public; 116 have been completely built over (happily by the Act of 1884 the erection of buildings on such spots has been forbidden, except for the purpose of enlarging the places of worship); 38 have been absorbed for various purposes (stable yards, private gardens, etc.); 23 are still used for interments, and the remaining 197 are closed.

For children almost more than grown-up people, an abundance of light and air, and especially space to run about in, is necessary. If this necessity wère satisfied, we should not see so many pinched, stunted bodies, with old-looking young faces about ns. A most striking example of the steady deterioration of the physique of this generation is to be found in the report of the Inspector General of Recruiting. In 1883, out of every thousand men who offered themselves for medical examination, 396.98 were rejected. This number rose the following year to 416.97 , and again two years later to 438.09 ; making in four years the serious increase of $41 \cdot 11$ of undersized, ill-developed, or unhealthy recruits. There are no less than 80 acres of playground in possession of the Board schools, but only nine of these grounds are open on Saturdays through the exertions of the Met. Public Gardens Association, which has obtained funds from private individuals for that purpose.

Whenever a garden is sufficiently large, as in the New Park of fourteen acres at Camberwell, a piece of it is set apart for the use of children only. These playgrounds are simply asphalted or gravelled (sometimes a few trees are planted), and seats, giant-strides, swings, and parallel bars are placed. Caretaker-gardeners are provided in all open spaces, those in the children's grounds being able to teach at stated times elementary gymnastics.

Besides the serious danger of used-up air to the bodily health of all Londoners, there is the depressing and degrading effect upon the minds of those who have to spend their entire lives with a very occasional glimpse of the country to refresh them. Most people will allow that good work of any kind cannot be accomplished by perpetual grind. The brain gets wearied and the body worn out, and if Jack is not to become the proverbial "dull boy," he must have a certain amount of relaxation of one sort or another. Now, after a hard day's work, say, in a factory, or driving an engine, perhaps one of the most entire and healthful rests is to get quietly away from the jarring of voices and rush of wheels, in a park or open square.

If in some densely-populated neighbourhood you walk through any of these gardens (in the early spring, or right through the summer and autumn, till it is too cold for the scantily-clad to sit in the open air), you will find them crowded with all manner of people who have come to snatch a little quiet to set them up for the next day's work. Little children are there all day, and as the afternoon wears on, they are joined by the tired, hard-worked elder folks, coming to pass a fow happy hours with their families in the enjoyment of these pleasant makeshifts for green fields and pastures new.

\section{Emmeline Wood Sieveking.}

\section{TUBERCULOSIS.}

That the present number of this journal contains so much relative to tuberculosis is not accidental, but of set purpose. The time is opportune. The French Congress in Paris, and the English sanitarians at Glasgow are alike making tuberculosis the chief theme of their discussions. English research on the subject receives an impetus from the recent work of Dr. Sims Woodhead, and even the public are in some degree appreciating the magnitude and practical bearing of the modern views.

The most impartial and complete summary of research on the nature of tubercle which has hitherto appeared is the elaborate and long paper of Professor Weichelsbaum, a first instalment of which appears on page 150 . Its publication in an English dress will give those who have not the necessary time or opportunity to wade through a mass of scattered literature, the means to become acquainted with the essence of all the contributions of real value which have appeared in various languages during the last five or six years. Whatever differences of opinion as to details of etiology or pathology still exist, there is now a general consensus among the leaders of preventive medicine that tubercle is but the local expression of a parasite, that the parasite is a bacillus of a distinctive kind; and farther, that it gains entrance to the animal body by being inhaled into the lungs, or taken in food, or occasionally by accidental cutaneous inoculation with tubercle-infected matter.

Had the bacillus been less protean in its manifestations-had it for instance only excited miliary tuberculosis, its nature and manner of spread would have found earlier acceptance; but the various chronic forms of the malady have been a difficulty. Phthisis will long continue to be regarded by many physicians as a non-contagious disease. Sufficient weight by the non-contagionists is not given to the fact verified by thousands of postmortems, that a large proportion of the population become infected with tubercle at some period of their lives without any very definito illness, and recover. A hostile colony is formed at the apex of the lung, the individual perhaps becomes a little thin, and has what he calls a "cold " on the chest; in time 